4

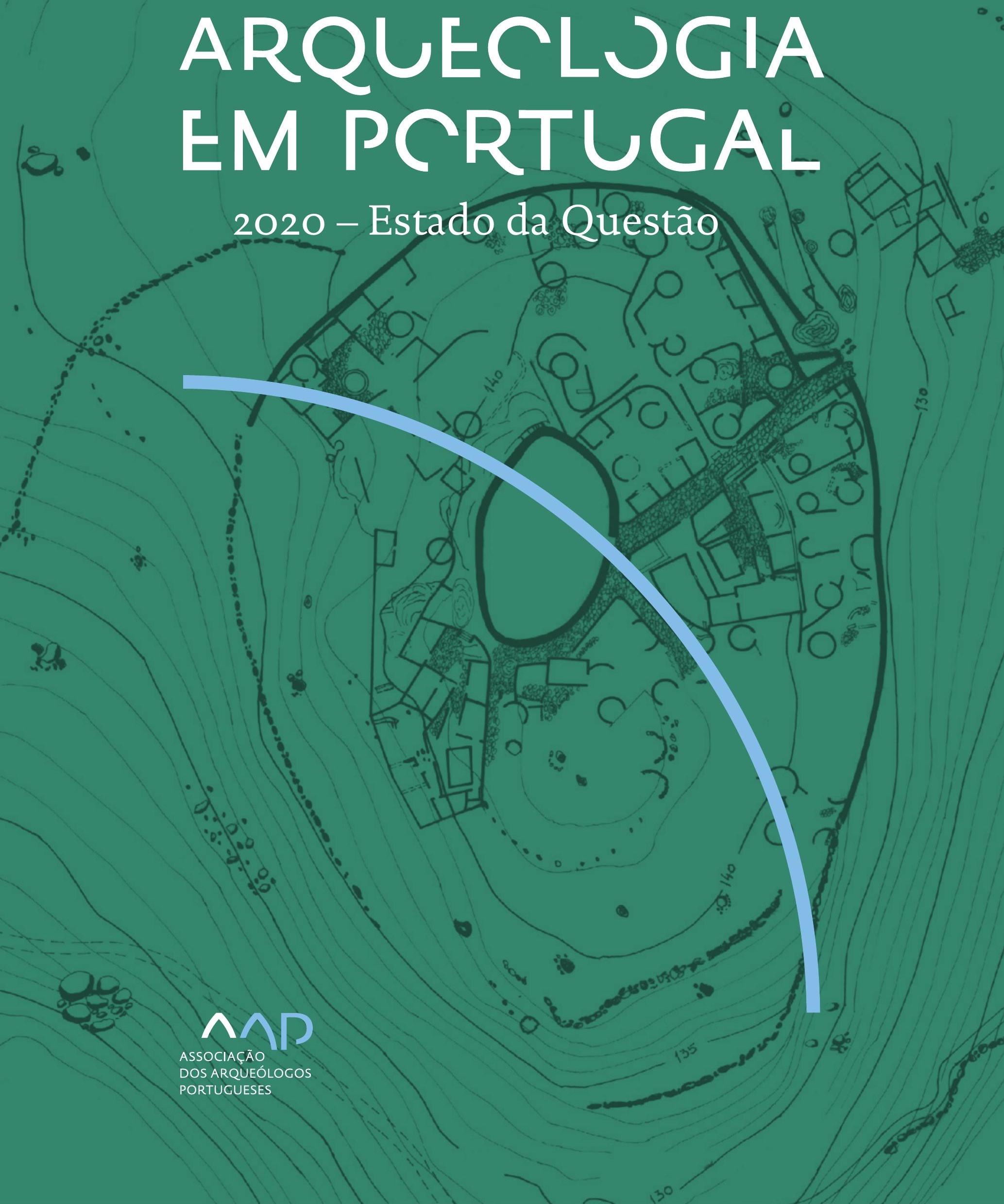


Coordenação editorial: José Morais Arnaud, César Neves e Andrea Martins Design gráfico: Flatland Design

AAP - ISBN: 978-972-9451-89-8

CITCEM - ISBN: 978-989-8970-25-1

Associação dos Arqueólogos Portugueses e CITCEM

Lisboa, 2020

O conteúdo dos artigos é da inteira responsabilidade dos autores. Sendo assim a Associação dos Arqueólogos Portugueses declina qualquer responsabilidade por eventuais equívocos ou questões de ordem ética e legal.

Desenho de capa:

Planta do castro de Monte Mozinho (Museu Municipal de Penafiel).

\section{$\hat{\wedge} \mathrm{P}$}

DOS ARQUEÓLOGOS PORTUGUESES

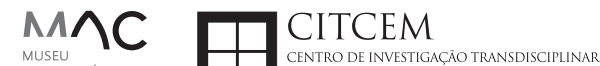
MUSEU
ARQUELLÓGICO
DO CARMO
U.PORTO

FLUP FACULDADE DE LETRAS
UNIVERSIDADE DO PORTO

Apoio

EC para a Ciência 


\section{Índice}

15 Prefácio

José Morais Arnaud

\section{Historiografia e Teoria}

17 Território, comunidade, memória e emoção: a contribuição da história da arqueologia (algumas primeiras e breves reflexões)

Ana Cristina Martins

25 Como descolonizar a arqueologia portuguesa?

Rui Gomes Coelho

41 Arqueologia e Modernidade: uma revisitação pessoal e breve de alguns aspetos da obra homónima de Julian Thomas de 2004

Vítor Oliveira Jorge

57 Dados para a História das Mulheres na Arqueologia portuguesa, dos finais do século XIX aos inícios do século XX: números, nomes e tabelas

Filipa Dimas / Mariana Diniz

73 Retractos da arqueologia portuguesa na imprensa: (in)visibilidades no feminino

Catarina Costeira / Elsa Luís

85 Arqueologia e Arqueólogos no Norte de Portugal Jacinta Bugalhão

101 Vieira Guimarães (1864-1939) e a arqueologia em Tomar: uma abordagem sobre o território e as gentes

João Amendoeira Peixoto / Ana Cristina Martins

115 Os memoráveis? A arqueologia algarvia na imprensa nacional e regional na presente centúria (2001-2019): características, visões do(s) passado(s) e a arqueologia

enquanto marca

Frederico Agosto / João Silva

129 A Evolução da Arqueologia Urbana e a Valorização Patrimonial no Barlavento Algarvio: Os casos de Portimão e Silves

Artur Mateus / Diogo Varandas / Rafael Boavida

\section{Gestão, Valorização e Salvaguarda do Património}

145 O Caderno Reivindicativo e as condições de trabalho em Arqueologia Miguel Rocha / Liliana Matias Carvalho / Regis Barbosa / Mauro Correia / Sara Simões / Jacinta Bugalhão / Sara Brito / Liliana Veríssimo Carvalho / Richard Peace / Pedro Peça / Cézer Santos

155 Os Estudos de Impacte Patrimonial como elemento para uma estratégia sustentável de minimização de impactes no âmbito de reconversões agrícolas Tiago do Pereiro

165 Salvaguarda de Património arqueológico em operações florestais: gestão e sensibilização Filipa Bragança / Gertrudes Zambujo / Sandra Lourenço / Belém Paiva / Carlos Banha / Frederico Tatá Regala / Helena Moura / Jacinta Bugalhão / João Marques / José Correia / Pedro Faria / Samuel Melro

179 Os valores do Património: uma investigação sobre os Sítios Pré-históricos de Arte Rupestre do Vale do Rio Côa e de Siega Verde José Paulo Francisco 
189 Conjugando recursos arqueológicos e naturais para potenciar as visitas ao Geoparque Litoral de Viana do Castelo (Noroeste de Portugal)

Hugo A. Sampaio / Ana M.S. Bettencourt / Susana Marinho / Ricardo Carvalhido

203 Áreas de Potencial Arqueológico na Região do Médio Tejo: Modelo Espacial Preditivo Rita Ferreira Anastácio / Ana Filipa Martins / Luiz Oosterbeek

223 Património Arqueológico e Gestão Territorial: O contributo da Arqueologia para a revisão do PDM de Avis

Ana Cristina Ribeiro

237 A coleção arqueológica do extinto Museu Municipal do Porto - Origens, Percursos e Estudos

Sónia Couto

251 Valpaços - uma nova carta arqueológica

Pedro Pereira / Maria de Fátima Casares Machado

263 Arqueologia na Cidade de Peniche

Adriano Constantino / Luís Rendeiro

273 Arqueologia Urbana: a cidade de Lagos como caso de Estudo Cátia Neto

285 Estratégias de promoção do património cultural subaquático nos Açores. O caso da ilha do Faial

José Luís Neto / José Bettencourt / Luís Borges / Pedro Parreira

297 Carta Arqueológica da Cidade Velha: Uma primeira abordagem

Jaylson Monteiro / Nireide Tavares / Sara da Veiga / Claudino Ramos / Edson Brito /

Carlos Carvalho / Francisco Moreira / Adalberto Tavares

311 Antropologia Virtual: novas metodologias para a análise morfológica e funcional Ricardo Miguel Godinho / Célia Gonçalves

\section{Didáctica da Arqueologia}

327 Como os projetos de Arqueologia podem contribuir para uma comunidade culturalmente mais consciente Alexandra Figueiredo / Claúdio Monteiro / Adolfo Silveira / Ricardo Lopes

337 Educação Patrimonial - Um cidadão esclarecido é um cidadão ativo! Ana Paula Almeida

351 A aproximação da Arqueologia à sala de aula: um caso de estudo no $3^{\circ}$ ciclo do Ensino Básico Luís Serrão Gil

363 Arqueologia 3.o - Pensar e comunicar a Arqueologia para um futuro sustentável Mónica Rolo

377 “Conversa de Arqueólogos" - Divulgar a Arqueologia em tempos de Pandemia Diogo Teixeira Dias

389 Escola Profissional de Arqueologia: desafios e oportunidades Susana Nunes / Dulcineia Pinto / Júlia Silva / Ana Mascarenhas

399 Os Museus de Arqueologia e os Jovens: a oferta educativa para o público adolescente Beatriz Correia Barata / Leonor Medeiros

411 O museu universitário como mediador entre a ciência e a sociedade: o exemplo da secção de arqueologia no Museu de História Natural e da Ciência da Universidade do Porto (MHNC-UP)

Rita Gaspar 
421 Museu de Lanifícios: Real Fábrica de Panos. Atividades no âmbito da Arqueologia Beatriz Correia Barata / Rita Salvado

427 Arqueologia Pública e o caso da localidade da Mata (Torres Novas) Cláudia Manso / Ana Rita Ferreira / Cristiana Ferreira / Vanessa Cardoso Antunes

431 Do sítio arqueológico ao museu: um percurso (também) didático Lídia Fernandes

447 Estão todos convidados para a Festa! E para dançar também... O projecto do Serviço Educativo do Museu Arqueológico do Carmo na $5^{\underline{a}}$ Edição da Festa da Arqueologia Rita Pires dos Santos

459 O “Clã de Carenque”, um projeto didático de arqueologia Eduardo Gonzalez Rocha

469 Mediação cultural: peixe que puxa carroça nas Ruínas Romanas de Troia Inês Vaz Pinto / Ana Patrícia Magalhães / Patrícia Brum / Filipa Santos

481 Didática Arqueológica, experiências do Projeto Mértola Vila Museu Maria de Fátima Palma / Clara Rodrigues / Susana Gómez / Lígia Rafael

\section{Arte Rupestre}

497 Os inventários de arte rupestre em Portugal Mila Simões de Abreu

513 O projeto FIRST-ART - conservação, documentação e gestão das primeiras manifestações de arte rupestre no Sudoeste da Península Ibérica: as grutas do Escoural e Maltravieso Sara Garcês / Hipólito Collado / José Julio García Arranz / Luiz Oosterbeek / António Carlos Silva / Pierluigi Rosina / Hugo Gomes / Anabela Borralheiro Pereira / George Nash / Esmeralda Gomes / Nelson Almeida / Carlos Carpetudo

523 Trabalhos de documentação de arte paleolítica realizados no âmbito do projeto PalæoCôa André Tomás Santos / António Fernando Barbosa / Luís Luís / Marcelo Silvestre / Thierry Aubry

537 Imagens fantasmagóricas, silhuetas elusivas: as figuras humanas na arte do Paleolítico Superior da região do Côa Mário Reis

$55^{1}$ Os motivos zoomórficos representados nas placas de tear de Vila Nova de São Pedro (Azambuja, Portugal) Andrea Martins / César Neves / José M. Arnaud / Mariana Diniz

571 Arte Rupestre do Monte de Góios (Lanhelas, Caminha). Síntese dos resultados dos trabalhos efectuados em 2007-2009 Mário Varela Gomes

599 Gravuras rupestres de barquiformes no Monte de S. Romão, Guimarães, Noroeste de Portugal Daniela Cardoso

613 Círculos segmentados gravados na Bacia do Rio Lima (Noroeste de Portugal): contributos para o seu estudo Diogo Marinho / Ana M.S. Bettencourt / Hugo Aluai Sampaio

631 Equídeos gravados no curso inferior do Rio Mouro, Monção (NW Portugal). Análise preliminar Coutinho, L.M. / Bettencourt, A.M.S / Sampaio, Hugo A.S

645 Paletas na Arte Rupestre do Noroeste de Portugal. Inventário preliminar Bruna Sousa Afonso / Ana M. S. Bettencourt / Hugo A. Sampaio 


\section{Pré-História}

661 O projeto Miño/Minho: balanço de quatro anos de trabalhos arqueológicos Sérgio Monteiro-Rodrigues / João Pedro Cunha-Ribeiro / Eduardo Méndez-Quintas / Carlos Ferreira / Pedro Xavier / José Meireles / Alberto Gomes / Manuel Santonja / Alfredo Pérez-González

677 A ocupação paleolítica da margem esquerda do Baixo Minho: a indústria lítica do sítio de Pedreiras 2 (Monção, Portugal) e a sua integração no contexto regional Carlos Ferreira / João Pedro Cunha-Ribeiro / Sérgio Monteiro-Rodrigues / Eduardo Méndez-Quintas / Pedro Xavier / José Meireles / Alberto Gomes / Manuel Santonja / Alfredo Pérez-González

693 O sítio acheulense do Plistocénico médio da Gruta da Aroeira Joan Daura / Montserrat Sanz / Filipa Rodrigues / Pedro Souto / João Zilhão

703 As sociedades neandertais no Barlavento algarvio: modelos preditivos com recurso aos SIG

Daniela Maio

715 A utilização de quartzo durante o Paleolítico Superior no território dos vales dos rios Vouga e Côa

Cristina Gameiro / Thierry Aubry / Bárbara Costa / Sérgio Gomes / Luís Luís / Carmen Manzano / André Tomás Santos

733 Uma perspetiva diacrónica da ocupação do concheiro do Cabeço da Amoreira (Muge, Portugal) a partir da tecnologia lítica Joana Belmiro / João Cascalheira / Célia Gonçalves

745 Novos dados sobre a Pré-história Antiga no concelho de Palmela. A intervenção arqueológica no sítio do Poceirão I

Michelle Teixeira Santos

757 Problemas em torno de Datas Absolutas Pré-Históricas no Norte do Alentejo Jorge de Oliveira

771 Povoamento pré-histórico nas áreas montanhosas do NO de Portugal: o Abrigo 1 de Vale de Cerdeira Pedro Xavier / José Meireles / Carlos Alves

783 Apreciação do povoamento do Neolítico Inicial na Baixa Bacia do Douro. A Lavra I (Serra da Aboboreira) como caso de estudo Maria de Jesus Sanches

797 O Processo de Neolitização na Plataforma do Mondego: os dados do Sector C do Outeiro dos Castelos de Beijós (Carregal do Sal)

João Carlos de Senna-Martinez / José Manuel Quintã Ventura / Andreia Carvalho / Cíntia Maurício

823 Novos trabalhos na Lapa da Bugalheira (Almonda, Torres Novas) Filipa Rodrigues / Pedro Souto / Artur Ferreira / Alexandre Varanda / Luís Gomes / Helena Gomes / João Zilhão

837 A pedra polida e afeiçoada do sítio do Neolítico médio da Moita do Ourives (Benavente, Portugal)

César Neves

857 Casal do Outeiro (Encarnação, Mafra): novos contributos para o conhecimento do povoamento do Neolítico final na Península de Lisboa.

Cátia Delicado / Carlos Maneira e Costa / Marta Miranda / Ana Catarina Sousa

873 Stresse infantil, morbilidade e mortalidade no sítio arqueológico do Neolítico Final/ Calcolítico ( $4^{\circ}$ e $3^{\circ}$ milénio a.C.) do Monte do Carrascal 2 (Ferreira do Alentejo, Beja) Liliana Matias de Carvalho / Sofia N. Wasterlain 
885 Come together: O Conjunto Megalítico das Motas (Monção, Viana do Castelo) e as expressões Campaniformes do Alto Minho Ana Catarina Basílio / Rui Ramos

899 Trabalhos arqueológicos no sítio Calcolítico da Pedreira do Poio Carla Magalhães / João Muralha / Mário Reis / António Batarda Fernandes

913 O sítio arqueológico de Castanheiro do Vento. Da arquitectura do sítio à arquitectura de um território João Muralha Cardoso

925 Estudo zooarqueológico das faunas do Calcolítico final de Vila Nova de São Pedro (Azambuja, Portugal): Campanhas de 2017 e 2018 Cleia Detry / Ana Catarina Francisco / Mariana Diniz / Andrea Martins / César Neves / José Morais Arnaud

943 As faunas depositadas no Museu Arqueológico do Carmo provenientes de Vila Nova de São Pedro (Azambuja): as campanhas de 1937 a 1967 Ana Catarina Francisco / Cleia Detry / César Neves / Andrea Martins / Mariana Diniz / José Morais Arnaud

959 Análise funcional de material lítico em sílex do castro de Vila Nova de S. Pedro (Azambuja, Portugal): uma primeira abordagem Rafael Lima

971 O recinto da Folha do Ouro 1 (Serpa) no contexto dos recintos de fossos calcolíticos alentejanos

António Carlos Valera / Tiago do Pereiro / Pedro Valério / António M. Monge Soares

\section{Proto-História}

987 Produção de sal marinho na Idade do Bronze do noroeste Português. Alguns dados para uma reflexão

Ana M. S. Bettencourt / Sara Luz / Nuno Oliveira / Pedro P. Simões / Maria Isabel C. Alves / Emílio Abad-Vidal

1001 A estátua-menir do Pedrão ou de São Bartolomeu do Mar (Esposende, noroeste de Portugal) no contexto arqueológico da fachada costeira de entre os rios Neiva e Cávado Ana M. S. Bettencourt / Manuel Santos-Estévez / Pedro Pimenta Simões / Luís Gonçalves

1015 O Castro do Muro (Vandoma/Baltar, Paredes) - notas para uma biografia de ocupação da Idade do Bronze à Idade Média

Maria Antónia D. Silva / Ana M. S. Bettencourt / António Manuel S. P. Silva / Natália Félix

1031 Do Bronze Final à Idade Média - continuidades e hiatos na ocupação de Povoados em Oliveira de Azeméis João Tiago Tavares / Adriaan de Man

1041 As faunas do final da Idade do Bronze no Sul de Portugal: leituras desde o Outeiro do Circo (Beja)

Nelson J. Almeida / Íris Dias / Cleia Detry / Eduardo Porfírio / Miguel Serra

1055 A Espada do Monte das Oliveiras (Serpa) - uma arma do Bronze Pleno do Sudoeste Rui M. G. Monge Soares / Pedro Valério / Mariana Nabais / António M. Monge Soares

1065 São Julião da Branca (Albergaria-a-Velha) - Investigação e valorização de um povoado do Bronze Final

António Manuel S. P. Silva / Paulo A. P. Lemos / Sara Almeida e Silva / Edite Martins de Sá

1083 Do castro de S. João ao Mosteiro de Santa Clara: notícia de uma intervenção arqueológica, em Vila do Conde Rui Pinheiro 
1095 O castro de Ovil (Espinho), um quarto de século de investigação - resultados e questões em aberto

Jorge Fernando Salvador / António Manuel S. P. Silva

1111 O Castro de Salreu (Estarreja), um povoado proto-histórico no litoral do Entre Douro e Vouga

Sara Almeida e Silva / António Manuel S. P. Silva / Paulo A. P. Lemos / Edite Martins de Sá

1127 Castro de Nossa Senhora das Necessidades (Sernancelhe): uma primeira análise artefactual Telma Susana O. Ribeiro

${ }_{1141}$ A cividade de Bagunte. O estado atual da investigação Pedro Brochado de Almeida

1153 Zoomorfos na cerâmica da Idade do Ferro no NW Peninsular: inventário, cronologias e significado Nuno Oliveira / Cristina Seoane

1163 Vasos gregos em Portugal: diferentes maneiras de contar a história do intercâmbio cultural na Idade do Ferro

Daniela Ferreira

1175 Os exotica da necrópole da Idade do Ferro do Olival do Senhor dos Mártires (Alcácer do Sal) no seu contexto regional

Francisco B. Gomes

\section{Antiguidade Clássica e Tardia}

1191 O uso de madeira como combustível no sítio da Quinta de Crestelos (Baixo Sabor): da Idade do Ferro à Romanização Filipe Vaz / João Tereso / Sérgio Simões Pereira / José Sastre / Javier Larrazabal Galarza / Susana Cosme / José António Pereira / Israel Espi

1207 Cultivos de Época Romana no Baixo Sabor: continuidade em tempos de mudança? João Pedro Tereso / Sérgio Simões Pereira / Filipe Santos / Luís Seabra / Filipe Vaz

1221 A casa romana na Hispânia: aplicação dos modelos itálicos nas províncias ibéricas Fernanda Magalhães / Diego Machado / Manuela Martins

1235 As pinturas murais romanas da Rua General Sousa Machado, n. ${ }^{5}$ 1, Chaves José Carvalho

1243 Trás do Castelo (Vale de Mir, Pegarinhos, Alijó) - Uma exploração agrícola romana do Douro

Tony Silvino / Pedro Pereira

1255 A sequência de ocupação no quadrante sudeste de Bracara Augusta: as transformações de uma unidade doméstica Lara Fernandes / Manuela Martins

1263 Os Mosaicos com decoração geométrica e geométrico-vegetalista dos sítios arqueológicos da área do Conuentus Bracaraugustanus. Novas abordagens quanto à conservação, restauro, decoração e datação Maria de Fátima Abraços / Licínia Wrench

1277 “Casa Romana” do Castro de São Domingos (Cristelos, Lousada): Escavação, Estudo e Musealização Paulo André de P. Lemos

1291 A arqueobotânica no Castro de Guifões (Matosinhos, Noroeste de Portugal): O primeiro estudo carpológico

Luís Seabra / Andreia Arezes / Catarina Magalhães / José Varela / João Pedro Tereso 
1305 Um Horreum Augustano na Foz do Douro (Monte do Castelo de Gaia, Vila Nova de Gaia) Rui Ramos

1311 Ponderais romanos na Lusitânia: padrões, formas, materiais e contextos de utilização Diego Barrios Rodríguez

1323 Um almofariz centro-itálico na foz do Mondego

Marco Penajoia

1335 Estruturas romanas de Carnide - Lisboa Luísa Batalha / Mário Monteiro / Guilherme Cardoso

1347 O contexto funerário do sector da "necrópole NO" da Rua das Portas de S. Antão (Lisboa): o espaço, os artefactos, os indivíduos e a sua interconectividade na interpretação do passado Sílvia Loja, José Carlos Quaresma, Nelson Cabaço, Marina Lourenço, Sílvia Casimiro, Rodrigo Banha da Silva, Francisca Alves-Cardoso

${ }_{1361}$ Povoamento em época Romana na Amadora - resultados de um projeto pluridisciplinar Gisela Encarnação / Vanessa Dias

1371 A Arquitectura Residencial em Mirobriga (Santiago do Cacém): contributo a partir de um estudo de caso Filipe Sousa / Catarina Felício

${ }_{1385}$ O fim do ciclo. Saneamento e gestão de resíduos nos edifícios termais de Mirobriga (Santiago do Cacém)

Catarina Felício / Filipe Sousa

1399 Balsa, Topografia e Urbanismo de uma Cidade Portuária Vítor Silva Dias / João Pedro Bernardes / Celso Candeias / Cristina Tété Garcia

1413 No Largo das Mouras Velhas em Faro (2017): novas evidências da necrópole norte de Ossonoba e da sua ocupação medieval Ricardo Costeira da Silva / Paulo Botelho / Fernando Santos / Liliana Nunes

1429 Instrumentos de pesca recuperados numa fábrica de salga em Ossonoba (Faro) Inês Rasteiro / Ricardo Costeira da Silva / Paulo Botelho

1439 A Necrópole Romana do Eirô, Duas Igrejas (Penafiel): intervenção arqueológica de 2016 Laura Sousa / Teresa Soeiro

1457 Ritual, descarte ou afetividade? A presença de Canis lupus familiaris na Necrópole Noroeste de Olisipo (Lisboa)

Beatriz Calapez Santos / Sofia Simões Pereira / Rodrigo Banha da Silva / Sílvia Casimiro / Cleia Detry / Francisca Alves Cardoso

1467 Dinâmicas económicas em Bracara na Antiguidade Tardia Diego Machado / Manuela Martins / Fernanda Magalhães / Natália Botica

1479 Cerâmicas e Vidros da Antiguidade Tardia do Edifício sob a Igreja do Bom Jesus (Vila Nova de Gaia) Joaquim Filipe Ramos

1493 Novos contributos para a topografia histórica de Mértola no período romano e na Antiguidade Tardia Virgílio Lopes

\section{8. Época Medieval}

1511 Cerâmicas islâmicas no Garb setentrional "português": algumas evidências e incógnitas Constança dos Santos / Helena Catarino / Susana Gómez / Maria José Gonçalves / Isabel Inácio / Gonçalo Lopes / Jacinta Bugalhão / Sandra Cavaco / Jaquelina Covaneiro / Isabel Cristina Fernandes / Ana Sofia Gomes 
1525 Contributo para o conhecimento da cosmética islâmica, em Silves, durante a Idade Média Rosa Varela Gomes

1537 Yábura e o seu território - uma análise histórico-arqueológica de Évora entre os séculos VIII-XII José Rui Santos

1547 A encosta sul do Castelo de Palmela - resultados preliminares da escavação arqueológica Luís Filipe Pereira / Michelle Teixeira Santos

1559 A igreja de São Lourenço (Mouraria, Lisboa): um conjunto de silos e de cerâmica medieval islâmica

Andreia Filipa Moreira Rodrigues

1571 O registo material de movimentações populacionais no Médio Tejo, durante os séculos XII-XIII. Dois casos de "sunken featured buildings", nos concelhos de Cartaxo e Torres Novas Marco Liberato / Helena Santos / Nuno Santos

1585 O nordeste transmontano nos alvores da Idade média. Notas para reflexão Ana Maria da Costa Oliveira

1601 Sepulturas escavadas na rocha do Norte de Portugal e do Vale do Douro: primeiros resultados do Projecto SER-NPVD

Mário Jorge Barroca / César Guedes / Andreia Arezes / Ana Maria Oliveira

1619 "Portucalem Castrum Novum" entre o Mediterrâneo e o Atlântico: o estudo dos materiais cerâmicos alto-medievais do arqueossítio da rua de D. Hugo, nํ. 5 (Porto) João Luís Veloso

1627 A Alta Idade Média na fronteira de Lafões: notas preliminares sobre a Arqueologia no Concelho de Vouzela

Manuel Luís Real / Catarina Tente

1641 Um conjunto cerâmico medieval fora de portas: um breve testemunho aveirense Susana Temudo

${ }_{1651}$ Os Lóios do Porto: uma perspetiva integrada no panorama funerário da Baixa Idade Média à Época Moderna em meios urbanos em Portugal

Ana Lema Seabra

1659 O Caminho Português Interior de Santiago como eixo viário na Idade Média Pedro Azevedo

1665 Morfologia Urbana: Um exercício em torno do Castelo de Ourém André Donas-Botto / Jaqueline Pereira

1677 Intervenção arqueológica na Rua Marquês de Pombal/Largo do Espírito Santo (Bucelas, Loures)

Florbela Estêvão / Nathalie Antunes-Ferreira / Dário Ramos Neves / Inês Lisboa

1691 O Cemitério Medieval do Poço do Borratém e a espacialidade funerária na cidade de Lisboa Inês Belém / Vanessa Filipe / Vasco Noronha Vieira / Sónia Ferro / Rodrigo Banha da Silva

1705 Um Espaço Funerário Conventual do séc. XV em Lisboa: o caso do Convento de São Domingos da Cidade Sérgio Pedroso / Sílvia Casimiro / Rodrigo Banha da Silva / Francisca Alves Cardoso

\section{9. Época Moderna e Contemporânea}

1721 Arqueologia Moderna em Portugal: algumas reflexões críticas em torno da quantificação de conjuntos cerâmicos e suas inferências históricas e antropológicas Rodrigo Banha da Silva / André Bargão / Sara da Cruz Ferreira

1733 Faianças de dois contextos entre os finais do século XVI e XVIII do Palácio dos Condes de Penafiel, Lisboa

Martim Lopes / Tomás Mesquita 
1747 Um perfil de consumo do século XVIII na foz do Tejo: O caso do Mercado da Ribeira, Lisboa Sara da Cruz Ferreira / Rodrigo Banha da Silva / André Bargão

1761 Os Cachimbos dos Séculos XVII e XVIII do Palácio Mesquitela e Convento dos Inglesinhos (Lisboa)

Inês Simão / Marina Pinto / João Pimenta / Sara da Cruz Ferreira / André Bargão / Rodrigo Banha da Silva

1775 "Tomar os fumos da erua que chamão em Portugal erua sancta». Estudo de Cachimbos provenientes da Rua do Terreiro do Trigo, Lisboa

Miguel Martins de Sousa / José Pedro Henriques / Vanessa Galiza Filipe

1787 Cachimbos de Barro Caulínitico da Sé da Cidade Velha (República de Cabo Verde)

Rodrigo Banha da Silva / João Pimenta / Clementino Amaro

1801 Algumas considerações sobre espólio não cerâmico recuperado no Largo de Jesus (Lisboa) Carlos Boavida

1815 Adereços de vidro, dos séculos XVI-XVIII, procedentes do antigo Convento de Santana de Lisboa (anéis, braceletes e contas)

Joana Gonçalves / Rosa Varela Gomes / Mário Varela Gomes

1837 Da ostentação, luxo e poder à simplicidade do uso quotidiano: arqueologia e simbologia de joias e adornos da Idade Moderna Portuguesa Jéssica Iglésias

1849 Os amuletos em Portugal - dos objetos às superstições: o coral vermelho Alexandra Vieira

1865 Cerâmicas de Vila Franca de Xira nos séculos XV e XVI Eva Pires

1879 «Não passa por teu o que me pertence». Marcas de individualização associadas a faianças do Convento de Nossa Senhora de Aracoeli, Alcácer do Sal Catarina Parreira / Íris Fragoso / Miguel Martins de Sousa

1891 Cerâmica de Leiria: alguns focos de produção

Jaqueline Pereira / André Donas-Botto

1901 Os Fornos na Rua da Biquinha, em Óbidos Hugo Silva / Filipe Oliveira

1909 A casa de Pêro Fernandes, contador dos contos de D. Manuel I: o sítio arqueológico da Silha do Alferes, Seixal (século XVI) Mariana Nunes Ferreira

1921 O Alto da Vigia (Sintra) e a vigilância e defesa da costa Alexandre Gonçalves / Sandra Santos

1937 O contexto da torre sineira da Igreja de Santa Maria de Loures Paulo Calaveira / Martim Lopes

1949 A Necrópole do Hospital Militar do Castelo de São Jorge e as práticas funerárias na Lisboa de Época Moderna Susana Henriques / Liliana Matias de Carvalho / Ana Amarante / Sofia N. Wasterlain

1963 SAND - Sarilhos Grandes Entre dois Mundos: o adro da Igreja e a Paleobiologia dos ossos humanos recuperados

Paula Alves Pereira / Roger Lee Jesus / Bruno M. Magalhães

1975 Expansão urbana da vila de Cascais no século XVII e XVIII: a intervenção arqueológica na Rua da Vitória no 15 a 17

Tiago Pereira / Vanessa Filipe

1987 Novos dados para o conhecimento do Urbanismo de Faro em época Moderna Ana Rosa 
1995 Um exemplo de Arqueologia Urbana em Alcoutim: o Antigo Edifício dos CTT Marco Fernandes / Marta Dias / Alexandra Gradim / Virgílio Lopes / Susana Gómez Martínez

2007 Palácio dos Ferrazes (Rua das Flores/Rua da Vitória, Porto): a cocheira de Domingos Oliveira Maia

Francisco Raimundo

2021 As muitas vidas de um edifício urbano: História, Arqueologia e Antropologia no antigo Recreatório Paroquial de Penafiel Helena Bernardo / Jorge Sampaio / Marta Borges

2035 O convento de Nossa Senhora da Esperança de Ponta Delgada: o contributo da arqueologia para o conhecimento de um monumento identitário João Gonçalves Araújo / N’Zinga Oliveira

2047 Arqueologia na ilha do Corvo... em busca da capela de Nossa Senhora do Rosário Tânia Manuel Casimiro / José Luís Neto / Luís Borges / Pedro Parreira

2059 Perdidos à vista da Costa. Trabalhos arqueológicos subaquáticos na Barra do Tejo Jorge Freire / José Bettencourt / Augusto Salgado

2071 Arqueologia marítima em Cabo Verde: enquadramento e primeiros resultados do projecto CONCHA

José Bettencourt / Adilson Dias / Carlos Lima / Christelle Chouzenoux / Cristóvão Fonseca / Dúnia Pereira / Gonçalo Lopes / Inês Coelho / Jaylson Monteiro / José Lima / Maria Eugénia Alves / Patrícia Carvalho / Tiago Silva

2085 Trabalhos arqueológicos na Cidade Velha (Ribeira Grande de Santiago, Cabo Verde): reflexões sobre um projecto de investigação e divulgação patrimonial André Teixeira / Jaylson Monteiro / Mariana Mateus / Nireide Tavares / Cristovão Fonseca / Gonçalo C. Lopes / Joana Bento Torres / Dúnia Pereira / André Bargão / Aurélie Mayer / Bruno Zélie / Carlos Lima / Christelle Chouzenoux / Inês Henriques / Inês Pinto Coelho / José Lima / Patrícia Carvalho / Tiago Silva

2103 A antiga fortificação de Quelba / Khor Kalba (E.A.U.). Resultados de quatro campanhas de escavações, problemáticas e perspectivas futuras Rui Carita / Rosa Varela Gomes / Mário Varela Gomes / Kamyar Kamyad

2123 Colónias para homens novos: arqueologia da colonização agrária fascista no noroeste ibérico Xurxo Ayán Vila / José Mạ . Señorán Martín 


\title{
ANTROPOLOGIA VIRTUAL: NOVAS METODOLOGIAS PARA A ANÁLISE MORFOLÓGICA E FUNCIONAL
}

\author{
Ricardo Miguel Godinho' ${ }^{1}$, Célia Gonçalves ${ }^{2}$
}

\begin{abstract}
RESUMO
A Bioantropologia examina frequentemente a morfologia óssea para inferir diversos aspectos do comportamento funerário e da paleobiologia de populações humanas passadas. A análise morfológica métrica (morfometria) convencional utiliza tipicamente medidas lineares, rácios e ângulos, contudo estas medidas não permitem a visualização das diferenças morfológicas em análise nem prever o desempenho mecânico dos ossos (que pode induzir diferenças morfológicas entre populações com diferentes hábitos). A Antropologia Virtual, combinando várias técnicas que se desenvolveram com a evolução tecnológica das últimas décadas, permite novas abordagens para a análise e compreensão das populações em estudo. Neste trabalho apresentamos uma breve síntese das técnicas mais importantes assimiladas pela Antropologia Virtual e de como esta pode melhorar a compreensão das populações em estudo.

Palavras-chave: Digitalização, Morfometria Geométrica, Arqueologia, Forma e função, Análise de Elementos Finitos.
\end{abstract}

\begin{abstract}
Bioanthropology examines skeletal morphology to infer diverse aspects of the funerary behaviour and palaeobiology of past populations. Conventional morphological metric (morphometrics) analysis has typically used linear measurements, ratios and angles. Yet, such quantifications do not allow visualization of the morphological differences nor prediction of the mechanical performance of bones (which may induce morphological differences between populations with diverse behaviours). Virtual Anthropology, which musters several techniques deriving from the exponential technological development of the past decades, provides new approaches to the analysis and understanding of the examined populations. Here, we summarize the techniques used in Virtual Anthropology and how this discipline may augment our understanding of the populations under study.
\end{abstract}

Keywords: Digitization, Geometric Morphometrics, Archaeology, Form-function, Finite Element Analysis.

\section{INTRODUÇÃO}

A Antropologia Biológica (Bioantropologia, também conhecida como Antropologia Física) estuda a dimensão biológica do Homem de uma perspectiva evolutiva e/ou bio-cultural (Jurmain, Kilgore \& Trevathan 2010). Neste contexto, o estudo morfológico de esqueletos humanos é fundamental para o conhecimento de populações passadas. A bioantropologia tem, assim, focado aspectos como a com- posição demográfica de populações (Chamberlain 2006; Bocquet-Appel \& Bar-Yosef 2008), comportamentos funerários (Valera et alii 2010; Filipe et alii 2013; Godinho, Gonçalves \& Valera 2019; Evangelista \& Godinho 2020), afinidades biológicas entre diferentes grupos (Scott \& Irish 2017; Delgado et alii 2019), padrões de actividade física (Ruff, Holt \& Trinkaus 2006; Henderson et alii 2016), adaptação mecânica do crânio à dieta (Carlson 1976; Carlson \& Van Gerven 1977), e aspectos paleopatológicos

1. ICArEHB, Universidade do Algarve; ricardomiguelgodinho@gmail.com

2. ICArEHB, Universidade do Algarve; cmgoncalves@ualg.pt 
(Ortner 2003; Rodríguez-Martín 2006; Waldron 2009). Para avaliar estes aspectos tem tipicamente analisado a morfologia esquelética usando frequentemente craveiras, tábuas osteométricas e fitas métricas (entre outros instrumentos). Embora estas abordagens mais convencionais sejam fundamentais para o conhecimento de populações passadas, o desenvolvimento tecnológico das últimas décadas possibilita a utilização de diversas técnicas que permitem a digitalização de espécimes (Weber \& Bookstein 2011; Katz \& Friess 2014; Errickson 2017), a sua reconstrução virtual (Benazzi et alii 2011; Benazzi et alii 2014; Amano et alii 2015; Godinho \& O’Higgins 2017; Godinho, O’Higgins \& Gonçalves 2020), a sua análise morfológica computadorizada (von Cramon-Taubadel 2011; Godinho et alii 2019; Godinho, Umbelino \& Gonçalves em preparação), e a realização de simulações mecânicas que permitem compreender a relação entre a forma e a função mecânica óssea (Godinho et alii 2017; Godinho et alii 2018; Godinho \& O’Higgins 2018; Godinho, Spikins \& O’Higgins 2018). Estas técnicas têm vindo a ser utilizadas na Antropologia Virtual, e outras áreas análogas, para realizar múltiplos estudos que de outra forma não seriam possíveis (O'Higgins et alii 2011; Weber \& Bookstein 2011; O'Higgins et alii 2012; Weber 2015; O’Higgins, Fitton \& Godinho 2019). Nas próximas secções sintetizamos algumas das técnicas utilizadas na Antropologia Virtual e como esta pode ser usada para oferecer novos dados sobre populações passadas.

\section{DIGITALIZAÇÃO}

A Antropologia Virtual utiliza tipicamente digitalizações dos espécimes físicos nas suas análises. O processo de digitalização pode ser realizado de diversas formas, incluindo digitalizações de superfície (através de fotogrametria, scanners a laser, scanners de luz estruturada) ou a Tomografia Axial Computadorizada (TAC; Weber \& Bookstein 2011; Katz \& Friess 2014; Errickson 2017). As digitalizações de superfície (Figura 1A e 1B) permitem a visualização e subsequente análise da superfície externa dos espécimes (ver abaixo Quantificação de forma). Embora este tipo de digitalização seja suficiente na maioria dos estudos, em que a análise foca a superfície exterior dos ossos, não permite visualizar e, consequentemente, analisar estruturas internas como, por exemplo, os seios paranasais do crânio ou os dife- rentes tecidos dentários (Weber \& Bookstein 2011). Para este efeito é necessário digitalizar os espécimes através de TAC (Figura ${ }_{1} C$ ) ou micro-TAC ( $\mu$ TAC). Estas técnicas permitem visualizar detalhadamente tanto a superfície quanto o interior dos espécimes (Figura 1D e 1E), embora com diferentes graus de resolução. A TAC também permite digitalizar vários espécimes (ou fragmentos de espécimes) ao mesmo tempo, sendo, assim, mais rápida que as digitalizações de superfície.

Este processo de digitalização de espécimes é fundamental porque:

i. diminui a necessidade de manuseamento directo dos espécimes, contribuindo assim para a sua preservação (Betts et alii 2011; Errickson 2017).

ii. salvaguarda os espécimes (pelo menos a sua informação morfológica, de acordo com a tecnologia utilizada) de eventuais desastres como aquele ocorrido no Museu Nacional do Brasil. Neste incêndio foi irremediavelmente destruído um inestimável acervo de $\sim 20$ milhões de espécimes (Cunha 2018; Kury, Giupponi \& Mendes 2018; França 2019; Silva 2019), incluindo o crânio de Luzia ( 1300o BP).

iii. permite análises subsequentes que de outra forma não seriam possíveis (ver secções seguintes).

\section{RECONSTRUÇÃO DE ESPÉCIMES FRAGMENTADOS E/OU INCOMPLETOS}

Os espécimes fósseis/arqueológicos estão frequentemente fragmentados e/ou incompletos (Gunz et alii 2009; Arbour \& Brown 2014; O’Higgins et alii 2019; Godinho, O’Higgins \& Gonçalves 2020). Este estado de conservação resulta frequentemente em amostras reduzidas e, subsequentemente, em resultados pouco fiáveis devido à reduzida representatividade das amostras utilizadas (Cardini \& Elton 2007; Brown \& Vavrek 2015; Cardini, Seetah \& Barker 2015). Para ultrapassar este problema a reconstrução física era frequente no passado (Weidenreich 1937; Leakey 1959; Tobias 1967; Tattersall \& Sawyer 1996), contudo esta abordagem apresenta problemas para a conservação dos espécimes, sendo o caso do crânio Neandertal de Le Moustier 1 um exemplo paradigmático de um espécime que foi progressivamente destruído devido ao seu repetido manuseamento e reconstrução física (Weber \& Bookstein 2011). Para além disso, a reconstrução física é fundamentalmente baseada na perícia individual do investigador e 
apresenta, assim, limitações na sua fiabilidade e replicabilidade (Gunz et alii 2009).

Actualmente, as técnicas da Antropologia Virtual permitem reconstruções que utilizam recursos computacionais, geométricos e estatísticos que são, assim, mais fiáveis e replicáveis (Weber \& Bookstein 2011; Weber 2015). Utilizando esses recursos é possível realizar "colagens virtuais" (Figura 2A e 2B) sem ser necessário aplicar forças físicas nos fragmentos (que podem causar mais fragmentação) nem utilizar colas ou consolidantes. É também possível explorar a simetria bilateral de diversas estruturas ósseas (e.g., crânios e mandíbulas) que mantenham um dos lados preservados (Gunz et alii 2009). Nestes casos reflecte-se o lado preservado para o lado fragmentado ou incompleto. Pode também utilizar-se a morfologia existente para estimar geometricamente a localização das regiões inexistentes utilizando "grelhas de transformação" (denominadas de Thin Plate Splines, TPS; Gunz et alii, 2009; Neeser et alii, 2009; Senck et alii, 2015; Godinho et alli, 2020). Nestes casos utiliza-se uma forma completa como referência e utilizam-se pontos anatómicos homólogos comuns para estimar a localização dos pontos anatómicos ausentes na forma alvo (Figura $2 \mathrm{C}$ ). Esta abordagem tem a vantagem de poder usar apenas um espécime como referência, mas também vários espécimes a partir dos quais é calculada uma média que é usada como referência (Gunz et alii 2009; Neeser, Ackermann \& Gain 2009; Godinho et alii 2020). Por fim, pode usar-se a regressão multivariada para se explorar a covariação estatística entre pontos anatómicos e assim utilizar a morfologia existente para estimar a morfologia inexistente (Gunz et alii 2009; Neeser et alii 2009; Arbour \& Brown 2014). Embora esta abordagem estatística possa proporcionar melhores resultados que a abordagem geométrica (isto é, a TPS) requer amostras de referência muito grandes e que são frequentemente inexistentes (como é comum em populações arqueológicas).

\section{QUANTIFICAÇÃO DE FORMA}

No contexto da Antrologia Biológica, a forma tem sido tipicamente quantificada através de medidas lineares (comprimentos, larguras, perímetros, ...). Estas medidas fornecem dados importantes para a análise morfológica e consequentemente continuam a ser usadas na Antropologia Virtual para analisar estruturas que não estariam facilmente disponíveis sem o recurso a, por exemplo, TAC e $\mu \mathrm{TAC}$. Estas tecnologias permitem expor, seccionar e analisar virtualmente estruturas internas, como os diferentes tecidos dentários (García-Campos et alii 2018; Godinho et alii 2019) e os seios paranasais cranianos (Rae, Koppe \& Stringer 2011; Godinho \& O’Higgins 2018; Buck et alii 2019), sem destruição dos espécimes. Porém, resultam fundamentalmente na análise do tamanho e não necessariamente da geometria esquelética (Adams, Rohlf \& Slice 2004; Slice 2005). Para esse efeito, têm-se utilizado rácios (por exemplo, o índice facial em que se dividem a largura e altura faciais) ou ângulos (por exemplo, o ângulo da base do crânio; Slice, 2005). Estas diferentes quantificações podem ser combinadas na análise multivariada da forma, contudo apresentam limitações estatísticas e não permitem a visualização das diferenças morfológicas em análise (Adams et alii 2004; Slice 2005). Em oposição à morfometria convencional, a Morfometria Geométrica (GM), uma das técnicas usadas na Antropologia Virtual, utiliza conjuntos de coordenadas (com duas ou três dimensões) de pontos anatómicos de espécimes (e.g., crânios ou mandíbulas; Figura $3 \mathrm{~A}$ ) para capturar a forma dos espécimes de interesse. Estes pontos devem ser homólogos (biologicamente "equivalentes") e relevantes para a questão que se pretende responder (O’Higgins 200o). A forma, da perspectiva da sua análise estatística, é composta por tamanho e geometria (Dryden \& Mardia 1998). A última (geometria) pode ser definida como as características morfológicas que são independentes do tamanho, localização e orientação (Zelditch et alii 2012). Após a recolha das coordenadas o primeiro passo da GM consiste na sobreposição das configurações de coordenadas utilizando o método da Análise Generalizada de Procrustes (GPA - Generalized Procrustes Analysis). Este método redimensiona os conjuntos de coordenadas removendo o tamanho (isométrico). Realiza também a sua translação e rotação (minimizando as distâncias entre os conjuntos de coordenadas) para remover o efeito da localização e orientação (Figura 3 B). As coordenadas originais são, assim, convertidas em variáveis geométricas que são subsequentemente utilizadas na análise morfológica através da estatística multivariada (Zelditch et alii 2012). Tipicamente, a GM utiliza a Análise de Componentes Principais (PCA) para reduzir dimensionalidade e avaliar a relação entre os diferentes espécimes. Esta abordagem é frequentemente com- 
binada com a utilização de grelhas de transformação para visualizar as diferenças morfológicas entre os diferentes espécimes (Figura ${ }_{3} \mathrm{C}$ ) e tem sido aplicada para examinar, por exemplo, diferenças morfológicas inter e intra-específicas (Delson et alii 2001; Bastir, O’Higgins \& Rosas 2007) e diferenças nos padrões de crescimento e desenvolvimento (Cobb \& O'Higgins 2007; Mitteroecker \& Bookstein 2009; Zollikofer \& Ponce de León 2010; Freidline, Gunz \& Hublin 2015). A regressão multivariada é também utilizada para examinar a relação entre variáveis de interesse, como por exemplo a relação entre tamanho e forma (Gonzalez, Perez \& Bernal 2011; Freidline et alii 2012; Freidline et alii 2015). A regressão por mínimos quadrados parciais (PLS - Partial Least Squares) também tem sido utilizada, por exemplo, para avaliar a relevância de aspectos biomecânicos e ecológicos (Noback, Harvati \& Spoor 2011; Noback \& Harvati 2015).

\section{ANÁLISE FUNCIONAL}

Uma das principais funções do esqueleto é converter as forças musculares em movimento e resistir às forças a que o corpo é permanentemente sujeito (Marieb 1992; Larsen 2002; Kerr 2010). Estas forças deformam os ossos (a uma escala micro-métrica), sendo estas deformações percepcionadas pelos ossos e desencadeando um processo de adaptação óssea que pode causar mudanças na morfologia óssea (Currey 2006; Cowin \& Doty 2007; Ethier \& Simmons 2007; Katz 2008). A Bioantropologia tem, assim, examinado a relação entre forma esquelética e função mecânica uma vez que diferenças na função mecânica óssea podem reflectir-se na morfologia (Ruff et alii 2006). Para esse efeito diversos investigadores têm usado a morfometria convencional e a GM para examinar, por exemplo, como diferenças na dieta se reflectem na morfologia craniana e mandibular (Carlson 1976; Carlson \& Van Gerven 1977; von Cramon-Taubadel 2011; Galland et alii 2016; Katz, Grote \& Weaver 2017), e como diferenças na mobilidade se reflectem na forma femoral (Püschel \& Benítez 2014). Tem-se também utilizado a morfologia seccional para examinar a relação entre morfologia mandibular e estratégia de subsistência/ dieta (May et alii 2018; Toro-Ibacache et alii 2019), e morfologia dos ossos dos membros inferiores e padrões de mobilidade (Ruff et alii 2015). Mais recentemente, com o desenvolvimento da imagiologia e da capacidade computacional, tem-se examinado o osso trabecular para inferir diferenças nos estímulos mecânicos de diferentes populações (Chirchir et alii 2015; Ryan \& Shaw 2015; Chirchir et alii 2017).

Estas abordagens têm proporcionado dados fundamentais para a compreensão da relação entre a forma esquelética e a sua função mecânica, e para a compreensão de como certas diferenças morfológicas entre diferentes populações se relacionam com factores mecânicos. Contudo, não permitem quantificar/estimar as deformações experienciadas pelos ossos (sendo estas que despoletam a adaptação mecânica óssea). Para estimar estas deformações, têm-se usado extensómetros em estudos in vivo (i.e., com espécimes vivos) ou in vitro (i.e., com ossos de indivíduos completamente esqueletizados; Hylander, Picq \& Johnson 1991; Ross \& Hylander 1996; Ross 2001). Estes estudos apresentam, porém, limitações éticas e técnicas. As limitações éticas devem-se à utilização de indivíduos vivos para a execução de experiências. As limitações técnicas devem-se à limitação do número de extensómetros que podem ser usados (o que inevitavelmente limita a área em que as deformações estão a ser medidas) e à impossibilidade da utilização de espécimes arqueológicos e/ou fósseis (a aplicação de forças físicas poderia danificar estes espécimes). Para ultrapassar estas limitações tem-se usado a Análise de Elementos Finitos (FEA - Finite Element Analysis,). A FEA é uma técnica numérica que se desenvolveu no contexto da engenharia, que permite simular cenários complexos de função mecânica e que estima as deformações experienciadas pelos espécimes (Fagan 1992; Logan 2007). Na FEA criam-se modelos virtuais ( $2 \mathrm{D}$ ou $\left.{ }_{3} D\right)$ que são constrangidos no espaço virtual, nos quais são modeladas as propriedades materiais (i.e., definidas características mecânicas como o módulo de Young e coeficiente de Poisson) dos diferentes materiais e aos quais se aplicam forças em que se especifica a sua magnitude e direcção. Naturalmente, toda a modelação virtual deverá replicar os casos reais, para que os resultados das simulações sejam fiáveis e relevantes. Para garantir esta fiabilidade são frequentemente realizados estudos de validação e sensibilidade em que se comparam os resultados de experiências no mundo real e em ambiente virtual. Os resultados destes estudos demonstram consistentemente que a FEA proporciona resultados fiáveis para a análise dos padrões de deformação (Strait et alii 2005; Fitton et alii 2015; Toro-Ibacache 
et alii 2016; Godinho et alii 2017). A FEA tem, assim, sido utilizada em estudos de evolução humana para analisar, por exemplo, a relação entre forma craniana e função mastigatória (Ledogar et alii 2016; Ledogar et alii 2017; Godinho et alii 2018; Godinho \& O’Higgins 2018; Godinho et alii 2018) (Figura 4).

\section{CONSIDERAÇÕES FINAIS}

A Antropologia Virtual cresceu a par do desenvolvimento exponencial das tecnologias de digitalização, da computação e de novas ferramentas estatísticas que permitem o processamento de grandes volumes de informação. A aglutinação de múltiplas novas técnicas potencializa a análise antropológica e, consequentemente a nossa compreensão da morfologia óssea e das populações que estuda. As actuais tecnologias de digitalização permitem a criação de modelos $3 \mathrm{D}$ que, quando incompletos, podem ser reconstruídos utilizando diversos programas de visualização e manipulação $3 \mathrm{D}$. A morfologia dos espécimes físicos pode ser capturada digital e detalhadamente utilizando novas técnicas de análise morfológica como a Morfometria Geométrica. Esta permite análises morfológicas mais completas que a morfometria convencional ao mesmo tempo que disponibiliza visualizações claras das diferenças morfológicas entre populações estudadas. Por fim, a função e adaptação mecânica dos ossos pode ser examinada através de análises detalhadas do osso trabecular ou de simulações mecânicas que permitem uma estimativa das deformações que despoletam a adaptação óssea a estímulos mecânicos.

\section{AGRADECIMENTOS}

Ricardo Miguel Godinho é financiado pelo Fundo Europeu de Desenvolvimento Regional (FEDER), através do Programa Operacional CRESC Algarve 2020, do Portugal 2020 (projecto ALG-01-0145FEDER-2968o e PTDC/HAR-ARQ/2968o/2017). Célia Gonçalves é financiada pela Fundação para a Ciência e Tecnologia (FCT, contrato DL 57/2016/ CP1361/CToo29).

\section{BIBLIOGRAFIA}

ADAMS, Dean C; ROHLF, F James; SLICE, Dennis E (2004) -Geometric morphometrics: Ten years of progress following the 'revolution'. Italian Journal of Zoology, 71:1, pp. 5-16.

AMANO, Hideki; KIKUCHI, Takeo; MORITA, Yusuke; KONDO, Osamu; SUZUKI, Hiromasa; PONCE DE LEÓN, Marcia S.; ZOLLIKOFER, Christoph P. E.; BASTIR, Markus; STRINGER, Chris; OGIHARA, Naomichi (2015) - Virtual reconstruction of the neanderthal amud 1 cranium. American Journal of Physical Anthropology, 158:2, pp. 185-197.

ARBOUR, Jessica H.; BROWN, Caleb M. (2014) - Incomplete specimens in geometric morphometric analyses. Methods in Ecology and Evolution, 5:1, pp. 16-26.

BASTIR, M.; O’HIGGINS, P.; ROSAS, A. (2007) - Facial ontogeny in neanderthals and modern humans. Proceedings of the Royal Society B-Biological Sciences, 274:1614, pp. 1125-1132.

BENAZZI, S.; BOOKSTEIN, F. L.; STRAIT, D. S.; WEBER, G. W. (2011) - A new oh5 reconstruction with an assessment of its uncertainty. Journal of Human Evolution, 61:1, pp. $75-88$.

BENAZZI, Stefano; GRUPPIONI, Giorgio; STRAIT, David S.; HUBLIN, Jean-Jacques (2014) - Technical note: Virtual reconstruction of $\mathrm{knm}$-er 1813 homo habilis cranium. American Journal of Physical Anthropology, 153:1, pp. 154-16o.

BETTS, Matthew W.; MASCHNER, Herbert D. G.; SCHOU, Corey D.; SCHLADER, Robert; HOLMES, Jonathan; CLEMENT, Nicholas; SMUIN, Michael (2011) - Virtual zooarchaeology: Building a web-based reference collection of northern vertebrates for archaeofaunal research and education. Journal of Archaeological Science, 38:4, pp. 755.e751-755.e759.

BOCQUET-APPEL, Jean-Pierre; BAR-YOSEF, Ofer (2008) - The neolithic demographic transition and its consequences. Springer Science \& Business Media.

BROWN, Caleb Marshall; VAVREK, Matthew J. (2015) Small sample sizes in the study of ontogenetic allometry; implications for palaeobiology. PeerJ, 3, p. e818.

BUCK, LT; STRINGER, CB; MACLARNON, AM; RAE, TC (2019) - Variation in paranasal pneumatisation between mid-late pleistocene hominins. Bulletins et Mémoires de la Société d'Anthropologie de Paris, 31, pp. 14-33.

CARDINI, Andrea; ELTON, Sarah (2007) - Sample size and sampling error in geometric morphometric studies of size and shape. Zoomorphology, 126:2, pp.121-134.

CARDINI, Andrea; SEETAH, Krish; BARKER, Graeme (2015) - How many specimens do i need? Sampling error in geometric morphometrics: Testing the sensitivity of means and variances in simple randomized selection experiments. Zoomorphology, 134:2, pp. 149-163. 
CARLSON, David S. (1976) - Temporal variation in prehistoric nubian crania. American Journal of Physical Anthropology, 45:3, pp. 467-484.

CARLSON, David S.; VAN GERVEN, Dennis P. (1977) Masticatory function and post-pleistocene evolution in nubia. American Journal of Physical Anthropology, 46:3, pp. 495-506.

CHAMBERLAIN, Andrew T (2006) - Demography in archaeology. New York: Cambridge University Press.

CHIRCHIR, Habiba; KIVELL, Tracy L.; RUFF, Christopher B.; HUBLIN, Jean-Jacques; CARLSON, Kristian J.; ZIPFEL, Bernhard; RICHMOND, Brian G. (2015) - Recent origin of low trabecular bone density in modern humans. Proceedings of the National Academy of Sciences, 112:2, pp. 366-371.

CHIRCHIR, Habiba; RUFF, Christopher B.; JUNNO, JuhoAntti; POTTS, Richard (2017) - Low trabecular bone density in recent sedentary modern humans. American Journal of Physical Anthropology, 162:3, p. e23138.

COBB, S. N.; O'HIGGINS, P. (2007) - The ontogeny of sexual dimorphism in the facial skeleton of the african apes. Journal of Human Evolution, 53:2, pp. 176-19o.

COWIN, Stephen; DOTY, Stephen (2007) - Tissue mechanics. New York: Springer.

CUNHA, Murilo Bastos da (2018) - Um museu em chamas: O caso do museu nacional do rio de janeiro. Revista Ibero-Americana de Ciência da Informação, 12:1, pp. 1-3.

CURREY, J. D. (2006) - Bones, structure and mechanics. New Jersey: Princeton University Press.

DELGADO, Miguel; RAMÍREZ, Luis Miguel; ADHIKARI, Kaustubh; FUENTES-GUAJARDO, Macarena; ZANOLLI, Clément; GONZALEZ-JOSÉ, Rolando; CANIZALES, Samuel; BORTOLINI, Maria-Catira; POLETTI, Giovanni; GALLO, Carla; ROTHHAMMER, Francisco; BEDOYA, Gabriel; RUIZ-LINARES, Andres (2019) - Variation in dental morphology and inference of continental ancestry in admixed latin americans. American Journal of Physical Anthropology, 168:3, pp. 438-447.

DELSON, E.; HARVATI, K.; REDDY, D.; MARCUS, L. F.; MOWBRAY, K.; SAWYER, G. J.; JACOB, T.; MARQUEZ, S. (2001) - The sambungmacan 3 homo erectus calvaria: A comparative morphometric and morphological analysis. Anatomical Record, 262:4, pp.380-397.

DRYDEN, I. L.; MARDIA, K. V. (1998) - Statistical shape analysis. Wiley-Blackwell.

ERRICKSON, David (2017) - Shedding light on skeletal remains: The use of structured light scanning for $3 \mathrm{~d}$ archiving. In ERRICKSON, D., THOMPSON, T.s eds. - Human remains: Another dimension. London: Academic Press pp. 93-101.

ETHIER, C. Ross; SIMMONS, Craig A. (2007) - Introductory biomechanics - from cells to organisms. New York: Cambridge University Press.
EVANGELISTA, Lucy Shaw; GODINHO, Ricardo Miguel (2020) - Estudo bio-antropológico do sepulcro 4 dos perdigões. In VALERA, A. C.s ed. - O sepulcro 4 dos perdigões. Um tholos da segunda metade do $3^{\circ}$ milénio a.C. Lisboa: Núcleo de Investigação Arqueológica (NIA) \& Era Arqueologia, S.A. pp. 57-102.

FAGAN, M. (1992) - Finite element analysis - theory and practice. Malaysia: Pearson Educational Ltd.

FILIPE, Victor; GODINHO, Ricardo Miguel; GRANJA, Raquel; RIBEIRO, Artur; VALERA, António (2013) - Bronze age funerary spaces in outeiro alto 2 (brinches, serpa, portugal): The hypogea cemetery. Zephyrus, 71, pp. 107-129.

FITTON, Laura C.; PRÔA, Miguel; ROWLAND, Charlie; TORO-IBACACHE, Viviana; O'HIGGINS, Paul (2015) The impact of simplifications on the performance of a finite element model of a macaca fascicularis cranium. The Anatomical Record, 298:1, pp. 107-121.

FRANÇA, Bianca (2019) - Acervos etnográficos do museu nacional: Preservação digital como sugestão pós incêndio.

FREIDLINE, S. E.; GUNZ, P.; HARVATI, K.; HUBLIN, J. J. (2012) - Middle pleistocene human facial morphology in an evolutionary and developmental context. Journal of Human Evolution, 63:5, pp. 723-740.

FREIDLINE, Sarah E.; GUNZ, Philipp; HUBLIN, JeanJacques (2015) - Ontogenetic and static allometry in the human face: Contrasting khoisan and inuit. American Journal of Physical Anthropology, 158:1, pp. 116-131.

GALLAND, Manon; VAN GERVEN, Denis P.; VON CRAMON-TAUBADEL, Noreen; PINHASI, Ron (2016) - 11, 0oo years of craniofacial and mandibular variation in lower nubia. Scientific Reports, 6, p. 31040.

GARCÍA-CAMPOS, Cecilia; MARTINÓN-TORRES, María; MARTÍN-FRANCÉS, Laura; MARTÍNEZ DE PINILLOS, Marina; MODESTO-MATA, Mario; PEREA-PÉREZ, Bernardo; ZANOLLI, Clément; LABAJO GONZÁLEZ, Elena; SÁNCHEZ SÁNCHEZ, José Antonio; RUIZ MEDIAVILLA, Elena; TUNIZ, Claudio; BERMÚDEZ DE CASTRO, José María (2018) - Contribution of dental tissues to sex determination in modern human populations. American Journal of Physical Anthropology, 166:2, pp. 459-472.

GODINHO, R. M.; O’HIGGINS, P (2017) - Virtual reconstruction of cranial remains: The h. Heidelbergensis, kabwe 1 fossil. In ERRICKSON, D., THOMPSON, T.s eds. - Human remains - another dimension: The application of $3 \mathrm{~d} \mathrm{im-}$ aging in funerary context. London: Elsevier pp. 135-147.

GODINHO, Ricardo Miguel; FITTON, Laura C.; TOROIBACACHE, Viviana; STRINGER, Chris B.; LACRUZ, Rodrigo S.; BROMAGE, Timothy G.; O'HIGGINS, Paul (2018) - The biting performance of homo sapiens and homo heidelbergensis. Journal of Human Evolution, 118, pp. 56-71.

GODINHO, Ricardo Miguel; GONÇALVES, David; VALERA, António Carlos (2019) - The preburning condi- 
tion of chalcolithic cremated human remains from the perdigões enclosures (portugal). International Journal of Osteoarchaeology, 29:5, pp. 706-717.

GODINHO, Ricardo Miguel; O’HIGGINS, Paul (2018) The biomechanical significance of the frontal sinus in kabwe 1 (homo heidelbergensis). Journal of Human Evolution, 114, pp. 141-153.

GODINHO, Ricardo Miguel; O’HIGGINS, Paul; GONÇALVES, Célia (2020) - Assessing the reliability of virtual reconstruction of mandibles. American Journal of Physical Anthropology, n/a:n/a, p. e24095.

GODINHO, Ricardo Miguel; OLIVEIRA-SANTOS, Inês; MANUEL FRANCISCO C, Pereira; MAURÍCIO, António; VALERA, António; GONÇALVES, David (2019) - Is enamel the only reliable hard tissue for sex metric estimation of burned skeletal remains in biological anthropology? Journal of Archaeological Science: Reports, 26, p. 101876.

GODINHO, Ricardo Miguel; SPIKINS, Penny; O’HIGGINS, Paul (2018) - Supraorbital morphology and social dynamics in human evolution. Nature Ecology $\&$ Evolution, 2:6, pp. 956-961.

GODINHO, Ricardo Miguel; TORO-IBACACHE, Viviana; FITTON, Laura C.; O'HIGGINS, Paul (2017) - Finite element analysis of the cranium: Validity, sensitivity and future directions. Comptes Rendus Palevol, 16:5, pp. 6oo-612.

GODINHO, Ricardo Miguel; UMBELINO, Cláudia; GONÇALVES, Célia (em preparação) - Mandibular morphological variation in the mesolithic.

GONZALEZ, Paula N.; PEREZ, S. Ivan; BERNAL, Valeria (2011) - Ontogenetic allometry and cranial shape diversification among human populations from south america. The Anatomical Record, 294:11, pp. 1864-1874.

GUNZ, P.; MITTEROECKER, P.; NEUBAUER, S.; WEBER, G. W.; BOOKSTEIN, F. L. (2009) - Principles for the virtual reconstruction of hominin crania. Journal of Human Evolution, 57:1, pp. 48-62.

HENDERSON, C. Y.; MARIOTTI, V.; PANY-KUCERA, D.; VILLOTTE, S.; WILCZAK, C. (2016) - The new 'coimbra method': A biologically appropriate method for recording specific features of fibrocartilaginous entheseal changes. 26:5, pp. 925-932.

HYLANDER, W. L.; PICQ, P. G.; JOHNSON, K. R. (1991) Masticatory-stress hypotheses and the supraorbital region of primates. American Journal of Physical Anthropology, 86:1, pp. 1-36.

JURMAIN, Robert; KILGORE, Lynn; TREVATHAN, Wenda (2010) - Essentials of physical anthropology. Cengage Learning.

KATZ, David C.; GROTE, Mark N.; WEAVER, Timothy D. (2017) - Changes in human skull morphology across the agricultural transition are consistent with softer diets in preindustrial farming groups. Proceedings of the National Academy of Sciences.

KATZ, David; FRIESS, Martin (2014) - Technical note: 3d from standard digital photography of human crania - a preliminary assessment. American Journal Of Physical Anthropology, 154:1, pp. 152-158.

KATZ, J (2008) - Mechanics of hard tissue. In PETERSON, D. R., BRONZINO, J. D.s eds. - Biomechanics: Principles and applications: Boca Raton, Florida: CRC Press pp. 1-20.

KERR, Andy (2010) - Introductory biomechanics. Edinburgh: Churchill Livingstone Elsevier.

KURY, Adriano B.; GIUPPONI, Alessandro P. L.; MENDES, Amanda C. (2018) - Immolation of museu nacional, rio de janeiro - unforgettable fire and irreplaceable loss. The Journal of Arachnology, 46:3, pp. 556-558.

LARSEN, William J. (2002) - Anatomy: Development, function, clinical correlations. Saint Louis: Saunders.

LEAKEY, Louis SB (1959) - A new fossil skull from olduvai. Nature, 184:4685, pp. 491-493.

LEDOGAR, Justin A.; BENAZZI, Stefano; SMITH, Amanda L.; WEBER, Gerhard W.; CARLSON, Keely B.; DECHOW, Paul C.; GROSSE, Ian R.; ROSS, Callum F.; RICHMOND, Brian G.; WRIGHT, Barth W.; WANG, Qian; BYRON, Craig; CARLSON, Kristian J.; DE RUITER, Darryl J.; PRYOR MCINTOSH, Leslie C.; STRAIT, David S. (2017) - The biomechanics of bony facial "buttresses" in south african australopiths: An experimental study using finite element analysis. The Anatomical Record, 300:1, pp. 171-195.

LEDOGAR, Justin A.; SMITH, Amanda L.; BENAZZI, Stefano; WEBER, Gerhard W.; SPENCER, Mark A.; CARLSON, Keely B.; MCNULTY, Kieran P.; DECHOW, Paul C.; GROSSE, Ian R.; ROSS, Callum F.; RICHMOND, Brian G.; WRIGHT, Barth W.; WANG, Qian; BYRON, Craig; CARLSON, Kristian J.; DE RUITER, Darryl J.; BERGER, Lee R.; TAMVADA, Kelli; PRYOR, Leslie C.; BERTHAUME, Michael A.; STRAIT, David S. (2016) - Mechanical evidence that australopithecus sediba was limited in its ability to eat hard foods. Nat Commun, 7.

LOGAN, DL (2007) - A first course in the finite element method. Delhi: Thomson.

MARIEB, EN (1992) - Human anatomy and physiology. Redwood City, California: Curnmings Publishing Company, Inc.

MAY, Hila; SELLA-TUNIS, Tanya; POKHOJAEV, Ariel; PELED, Nathan; SARIG, Rachel (2018) - Changes in mandible characteristics during the terminal pleistocene to holocene levant and their association with dietary habits. Journal of Archaeological Science: Reports.

MITTEROECKER, P.; BOOKSTEIN, F. (2009) - The ontogenetic trajectory of the phenotypic covariance matrix, with examples from craniofacial shape in rats and humans. Evolution, 63:3, pp. 727-737. 
NEESER, Rudolph; ACKERMANN, Rebecca Rogers; GAIN, James (2009) - Comparing the accuracy and precision of three techniques used for estimating missing landmarks when reconstructing fossil hominin crania. American Journal of Physical Anthropology, 140:1, pp. 1-18.

NOBACK, Marlijn L.; HARVATI, Katerina (2015) - Covariation in the human masticatory apparatus. The Anatomical Record, 298:1, pp. 64-84.

NOBACK, Marlijn L.; HARVATI, Katerina; SPOOR, Fred (2011) - Climate-related variation of the human nasal cavity. American Journal of Physical Anthropology, 145:4, pp. 599-614.

O'HIGGINS, P. (200o) - The study of morphological variation in the hominid fossil record: Biology, landmarks and geometry. Journal of Anatomy, 197, pp. 103-120.

O’HIGGINS, P.; COBB, S. N.; FITTON, L. C.; GRONING, F.; PHILLIPS, R.; LIU, J.; FAGAN, M. J. (2011) - Combining geometric morphometrics and functional simulation: An emerging toolkit for virtual functional analyses. Journal of Anatomy, 218:1, pp. 3-15.

O’HIGGINS, P.; FITTON, L. C.; PHILLIPS, R.; SHI, J. F.; LIU, J.; GRONING, F.; COBB, S. N.; FAGAN, M. J. (2012) - Virtual functional morphology: Novel approaches to the study of craniofacial form and function. Evolutionary Biology, 39:4, pp. 521-535.

O’HIGGINS, Paul; FITTON, Laura C.; GODINHO, Ricardo Miguel (2019) - Geometric morphometrics and finite elements analysis: Assessing the functional implications of differences in craniofacial form in the hominin fossil record. Journal of Archaeological Science, 101, pp. 159-168.

ORTNER, Donald J. (2003) - Identification of pathological conditions in human skeletal remains. San Diego: Academic Press.

PÜSCHEL, Thomas A; BENÍTEZ, Hugo A (2014) - Femoral functional adaptation: A comparison between hunter gatherers and farmers using geometric morphometrics. International Journal of Morphology, 32, pp. 627-633.

RAE, Todd C.; KOPPE, Thomas; STRINGER, Chris B. (2011) - The neanderthal face is not cold adapted. Journal of Human Evolution, 6o:2, pp. 234-239.

RODRÍGUEZ-MARTÍN, Conrado (2006) - Identification and differential diagnosis of traumatic lesions of the skeleton. In SCHMITT, A., CUNHA, E., PINHEIRO, J.s eds. - Forensic anthropology and medicine: Complementary sciences from recovery to cause of death. Totowa, NJ: Humana Press pp. 197-221.

ROSS, C. F. (2001) - In vivo function of the craniofacial haft: The interorbital "pillar". American Journal of Physical Anthropology, 116:2, pp. 108-139.

ROSS, C. F.; HYLANDER, W. L. (1996) - In vivo and in vitro bone strain in the owl monkey circumorbital region and the function of the postorbital septum. American Journal of Physical Anthropology, 101:2, pp. 183-215.

RUFF, Christopher B.; HOLT, Brigitte; NISKANEN, Markku; SLADEK, Vladimir; BERNER, Margit; GAROFALO, Evan; GARVIN, Heather M.; HORA, Martin; JUNNO, Juho-Antti; SCHUPLEROVA, Eliska; VILKAMA, Rosa; WHITTEY, Erin (2015) - Gradual decline in mobility with the adoption of food production in europe. Proceedings of the National Academy of Sciences, 112:23, p. 7147.

RUFF, Christopher; HOLT, Brigitte; TRINKAUS, Erik (2006) - Who's afraid of the big bad wolff? "Wolff's law" and bone functional adaption. American Journal of Physical Anthropology, 129, pp. 484-498.

RYAN, Timothy M.; SHAW, Colin N. (2015) - Gracility of the modern homo sapiens skeleton is the result of decreased biomechanical loading. Proceedings of the National Academy of Sciences, 112:2, pp. 372-377.

SCOTT, G Richard; IRISH, Joel D (2017) - Human tooth crown and root morphology. Cambridge University Press.

SILVA, Daniel B. Domingues da (2019) - Lost to fire: The african collection of the national museum of brazil. African Arts, 52:3, pp. 13-15.

Author (2005) - Modern morphometrics in physical anthropology. SLICE, D., Ed. New York: Kluwer Academic.

STRAIT, D. S.; WANG, Q.; DECHOW, P. C.; ROSS, C. F.; RICHMOND, B. G.; SPENCER, M. A.; PATEL, B. A. (2005) - Modeling elastic properties in finite element analysis: How much precision is needed to produce an accurate model? Anatomical Record Part a-Discoveries in Molecular Cellular and Evolutionary Biology, 283A:2, pp. 275-287.

TATTERSALL, Ian; SAWYER, G. J. (1996) - The skull of "sinanthropus" from zhoukoudian, china: A new reconstruction. Journal of Human Evolution, 31:4, pp. 311-314.

TOBIAS, P. V. (1967) - Olduvai gorge vol. 2: The cranium and maxillary dentition of australopithecus (zinjanthropus) boisei. Cambridge: Cambridge University Press.

TORO-IBACACHE, Viviana; FITTON, Laura C.; FAGAN, Michael J.; O’HIGGINS, Paul (2016) - Validity and sensitivity of a human cranial finite element model: Implications for comparative studies of biting performance. Journal of Anatomy, 228:1, pp. 70-84.

TORO-IBACACHE, Viviana; UGARTE, Francisco; MORALES, Cristina; EYQUEM, Andrea; AGUILERA, José; ASTUDILLO, Williams (2019) - Dental malocclusions are not just about small and weak bones: Assessing the morphology of the mandible with cross-section analysis and geometric morphometrics. Clinical Oral Investigations.

VALERA, António; GODINHO, Ricardo Miguel; CALVO, Ever; MORO BERRAQUERO, Javier; FILIPE, Victor; SANTOS, Helena (2010) - Um mundo em negativo: Fossos, fossas e hipogeus entre o neolítico final e a idade do bronze 
na margem esquerda do guadiana (brinches, serpa). In SILVA, A. C., REGALA, F. T., MARTINHO, M. eds. Beja: EDIA pp. 55-73.

VON CRAMON-TAUBADEL, Noreen (2011) - Global human mandibular variation reflects differences in agricultural and hunter-gatherer subsistence strategies. Proceedings of the National Academy of Sciences, 108:49, pp. 19546-19551.

WALDRON, Tony (2009) - Palaeopathology. Cambridge: Cambridge University Press.

WEBER, G. W.; BOOKSTEIN, F. L. (2011) - Virtual anthropology - a guide for a new interdisciplinary field. Wien: Springer-Verlag.

WEBER, Gerhard W. (2015) - Virtual anthropology. American Journal of Physical Anthropology, 156, pp. 22-42.

WEIDENREICH, Franz (1937) - Reconstruction of the entire skull of an adult female individual of sinanthropus pekinensi. Nature, 140:3554, p. 1010.

ZELDITCH, Miriam L.; SWIDERSKI, Donald L.; SHEETS, H. David; FINK, William L. (2012) - Geometric morphometrics for biologists: A primer. New York: Elsevier.

ZOLLIKOFER, Christoph P. E.; PONCE DE LEÓN, Marcia S. (2010) - The evolution of hominin ontogenies. Seminars in Cell \& Developmental Biology, 21:4, pp.441-452. 

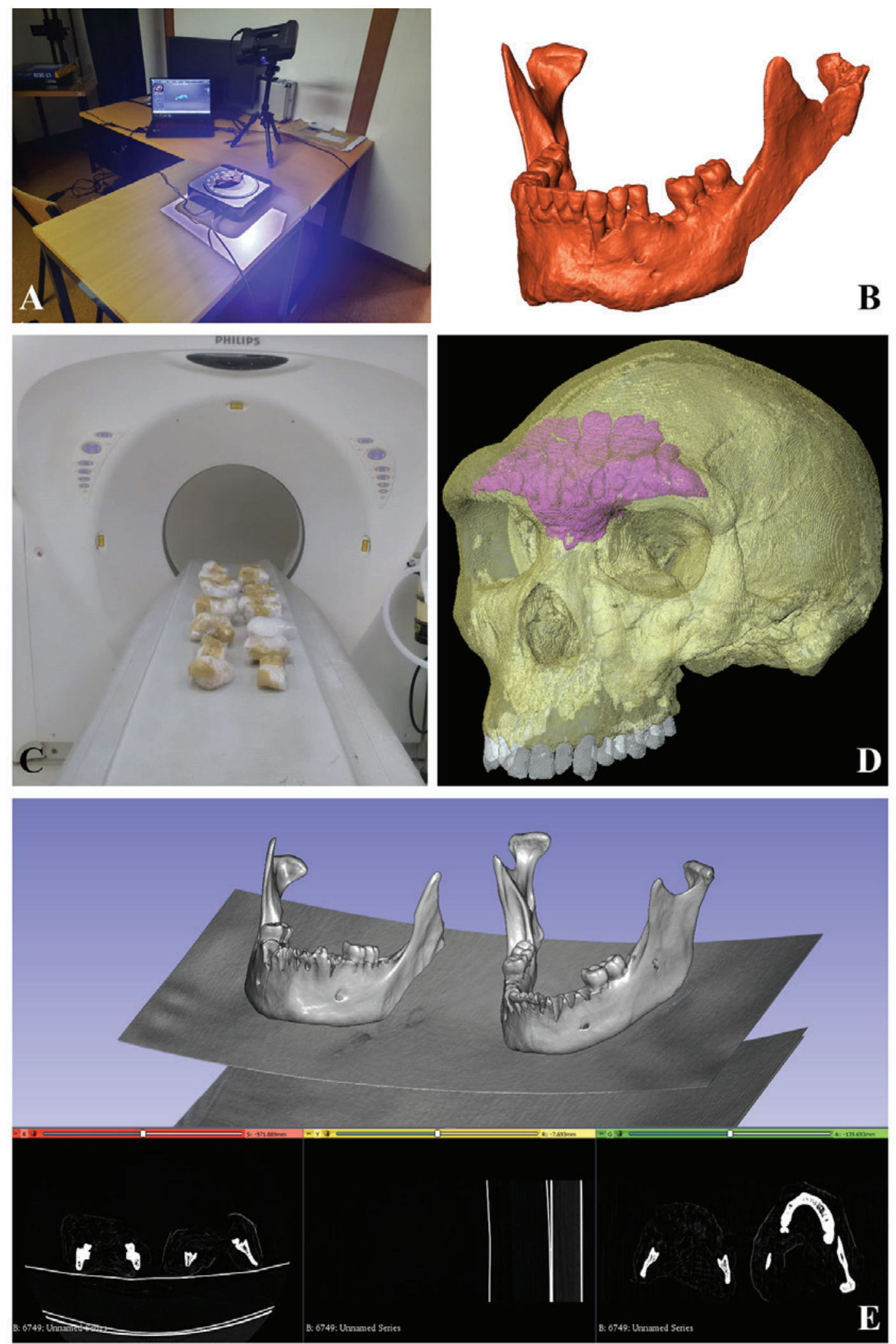

Figura 1 - Exemplos de digitalização de espécimes. A) Processo de digitalização de superfície de uma mandíbula humana. B) Resultado da digitalização de superfície de uma mandíbula humana. C) Processo de digitalização através de TAC, com vários espécimes sobre a plataforma do scanner TAC para digitalização. D) Segmentação e renderização de um crânio fóssil hominíneo (Kabwe 1, Homo heidelbergensis) com individualização dos seios frontais (destacados a roxo). C) Renderização de duas mandíbulas digitalizadas através de TAC e das respectivas secções tomográficas. 

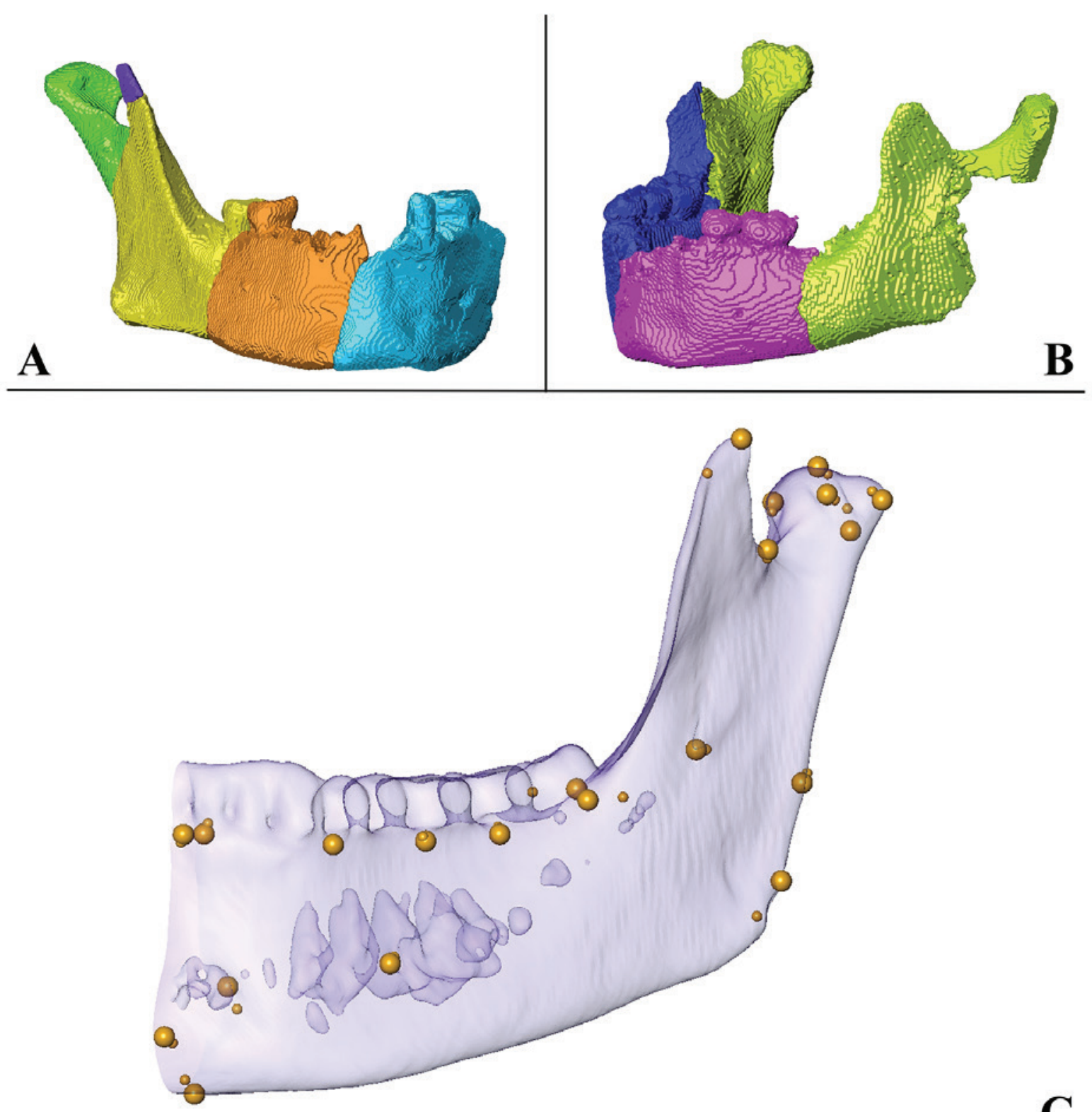

Figura 2 - Exemplos de reconstrução virtual de mandíbulas humanas. A e B) Exemplos de colagens virtuais de duas mandíbulas humanas. C) Exemplo de estudo sobre a fiabilidade da estimativa da localização de ponto anatómicos utilizando a abordagem geométrica (i.e., TPS). As esferas de maior dimensão representam a localização original e as esferas de pequena dimensão a localização estimada desses mesmos pontos anatómicos. 

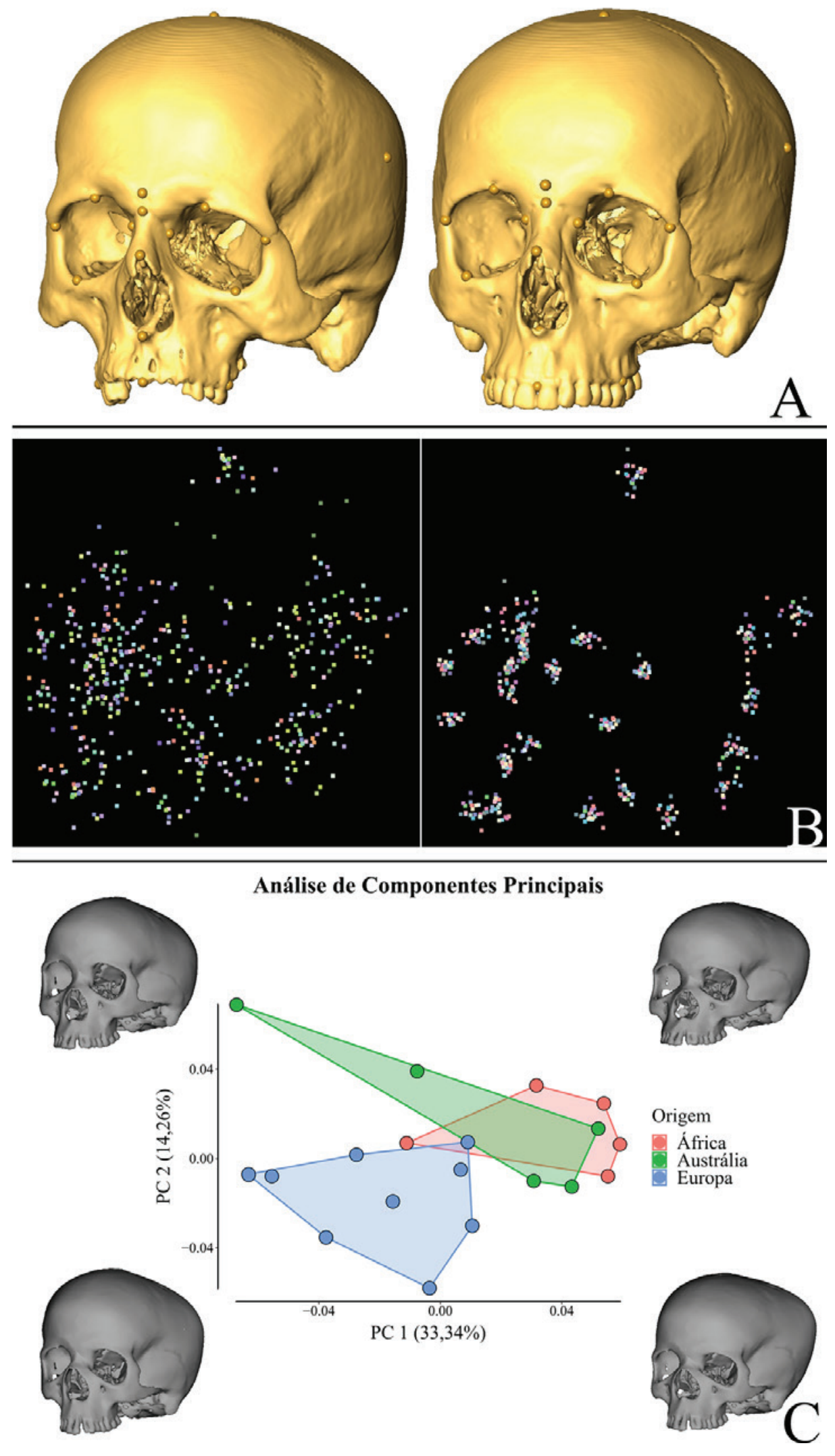

Figura 3 - Exemplo de análise GM. A) Dois crânios em que foi recolhido um conjunto de coordenadas de pontos homólogos. B) Exemplo de GPA com 20 espécimes (crânios, entre os quais os ilustrados em A); a imagem à esquerda ilustra o conjunto de pontos homólogos pré sobreposição e a imagem à direita o conjunto de pontos homólogos sobrepostos (cada ponto representa uma coordenada tridimensional). C) PCA com os espécimes sobrepostos em que cada ponto representa um indivíduo; as cores codificam a origem geográfica dos espécimes e as imagens dos crânios representam as diferenças morfológicas nos extremos dos eixos dos componentes principais. 


\section{Homo sapiens}

(espécime recente)
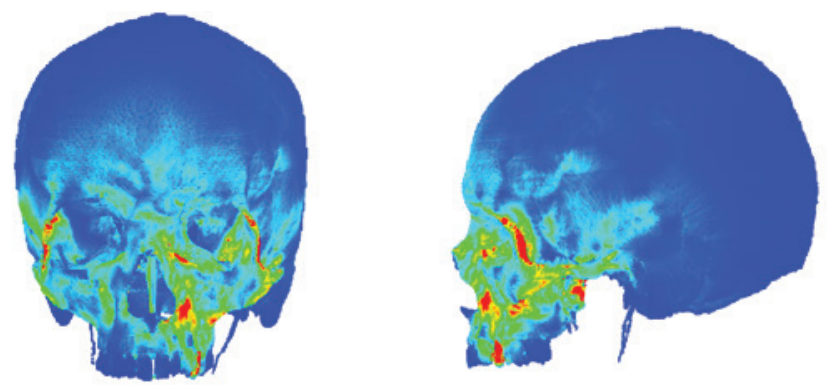

\section{Homo heidelbergensis} (Kabwe 1)
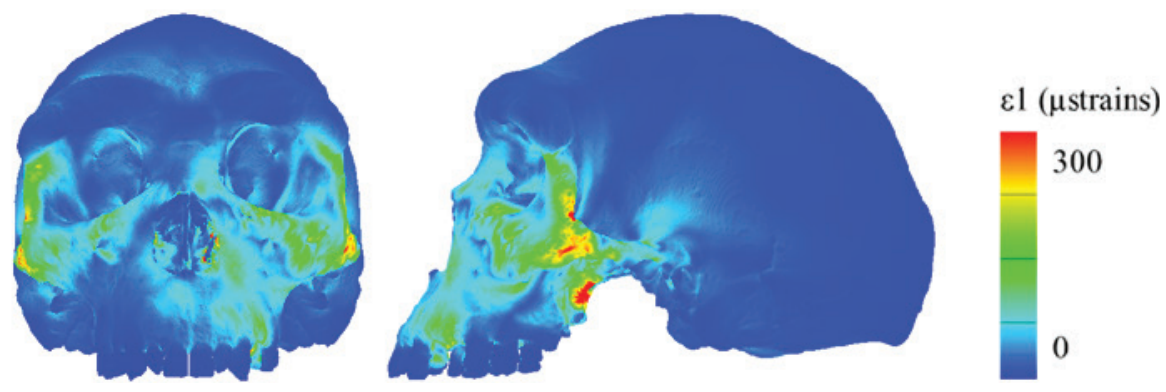

Figura 4 - Exemplo de FEA em que se compara o desempenho mecânico de um H. sapiens com um H. heidelbergensis (imagens não estão à escala). Neste caso (deformações principais máximas), as cores frias representam deformações de reduzida magnitude e as cores quentes deformações de elevada magnitude. 


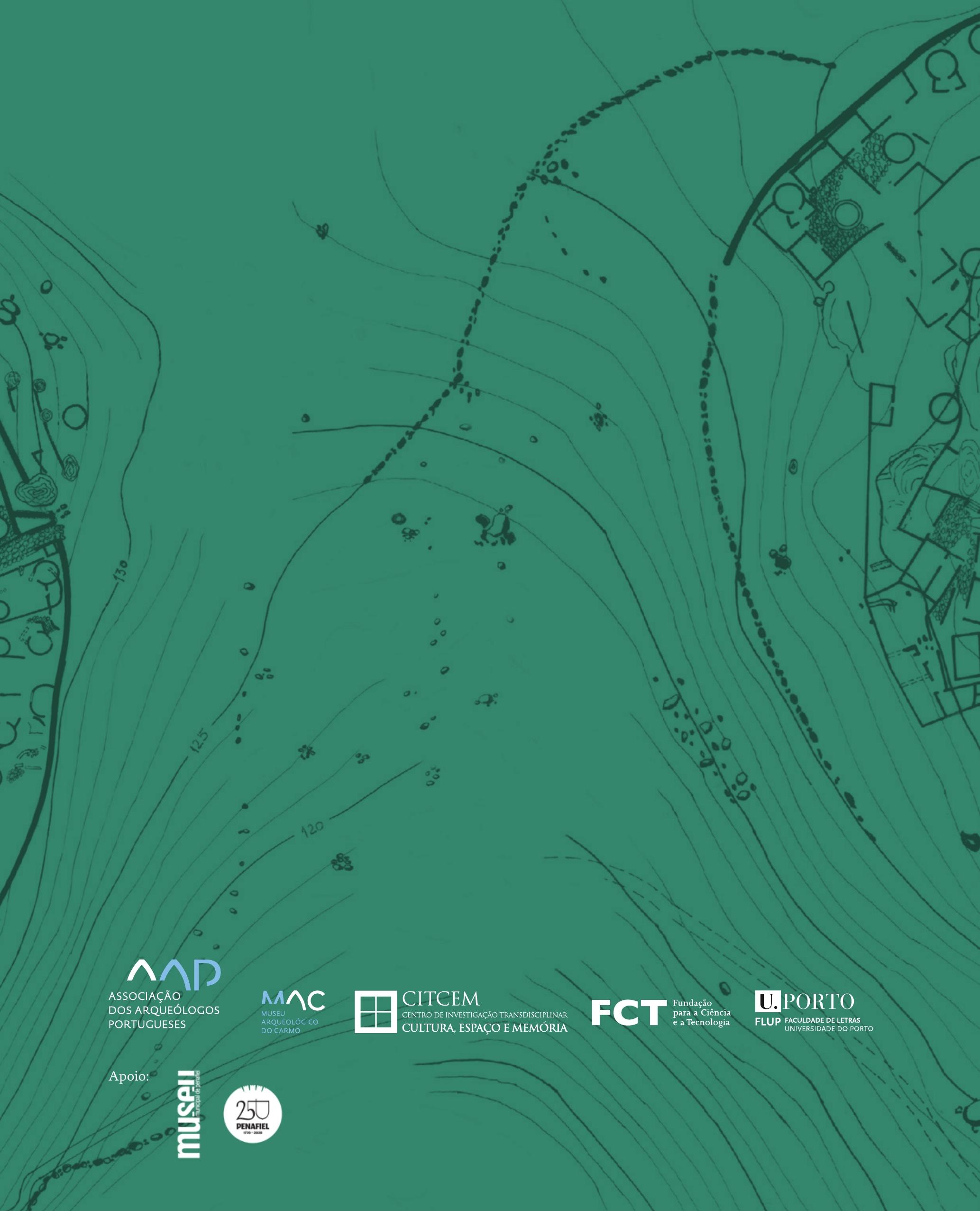

